\title{
COVID-19 case fatality risk by age and gender in a high testing setting in Latin America: Chile, March-August 2020
}

\author{
Eduardo A. Undurraga ${ }^{1,2^{*}} \mathbb{D}$, Gerardo Chowell ${ }^{3}$ and Kenji Mizumoto ${ }^{4,5}$
}

\begin{abstract}
Background: Early severity estimates of coronavirus disease 2019 (COVID-19) are critically needed to assess the potential impact of the ongoing pandemic in different demographic groups. Here we estimate the real-time delayadjusted case fatality rate across nine age groups by gender in Chile, the country with the highest testing rate for COVID-19 in Latin America.

Methods: We used a publicly available real-time daily series of age-stratified COVID-19 cases and deaths reported by the Ministry of Health in Chile from the beginning of the epidemic in March through August 31, 2020. We used a robust likelihood function and a delay distribution to estimate real-time delay-adjusted case-fatality risk and estimate model parameters using a Monte Carlo Markov Chain in a Bayesian framework.

Results: As of August 31, 2020, our estimates of the time-delay adjusted case fatality rate (CFR) for men and women are 4.16\% [95\% Credible Interval (Crl): 4.09-4.24\%] and 3.26\% (95\% Crl: 3.19-3.34\%), respectively, while the overall estimate is 3.72\% (95\% Crl: 3.67-3.78\%). Seniors aged 80 years and over have an adjusted CFR of $56.82 \%$ (95\% Crl: 55.25-58.34\%) for men and 41.10\% (95\% Crl: 40.02-42.26\%) for women. Results showed a peak in estimated CFR during the June peak of the epidemic. The peak possibly reflects insufficient laboratory capacity, as illustrated by high test positivity rates (33\% positive 7-day average nationally in June), which may have resulted in lower reporting rates.

Conclusions: Severity estimates from COVID-19 in Chile suggest that male seniors, especially among those aged $\geq 70$ years, are being disproportionately affected by the pandemic, a finding consistent with other regions. The ongoing pandemic is imposing a high death toll in South America, and Chile has one of the highest reported mortality rates globally thus far. These real-time estimates may help inform public health officials' decisions in the region and underscore the need to implement more effective measures to ameliorate fatality.
\end{abstract}

Keywords: COVID-19, Chile, Death risk by age group, Time-delay adjusted case fatality rate, Latin America

\section{Background}

The coronavirus disease 2019 (COVID-19) pandemic has strained or overwhelmed health systems across the world $[1,2]$, with about 25.5 million COVID-19 cases and 850

\footnotetext{
${ }^{*}$ Correspondence: eundurra@uc.cl

${ }^{1}$ Escuela de Gobierno, Pontificia Universidad Católica de Chile, Vicuña Mackenna 4860, Macul, CP 7820436 Santiago, Región Metropolitana, Chile

Full list of author information is available at the end of the article
}

thousand deaths as of August 31, 2020 [3, 4]. The first case in South America of severe acute respiratory syndrome coronavirus 2 (SARS-CoV-2) infection, the cause of COVID-19, was reported on February 25 in São Paulo, Brazil, a travel hub in the region [5]. A few weeks later, countries in the region had imposed major epidemic control measures, such as closed borders, restricted travel, closure of schools and universities, and enforced lockdowns [6, 7]. Despite these measures, the ongoing coronavirus pandemic has already imposed a high

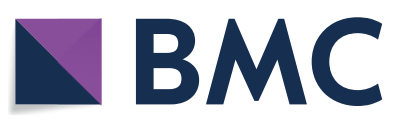

(c) The Author(s) 2021. Open Access This article is licensed under a Creative Commons Attribution 4.0 International License, which permits use, sharing, adaptation, distribution and reproduction in any medium or format, as long as you give appropriate credit to the original author(s) and the source, provide a link to the Creative Commons licence, and indicate if changes were made. The images or other third party material in this article are included in the article's Creative Commons licence, unless indicated otherwise in a credit line to the material. If material is not included in the article's Creative Commons licence and your intended use is not permitted by statutory regulation or exceeds the permitted use, you will need to obtain permission directly from the copyright holder. To view a copy of this licence, visit http://creativecommons.org/licenses/by/4.0/. The Creative Commons Public Domain Dedication waiver (http://creativeco mmons.org/publicdomain/zero/1.0/) applies to the data made available in this article, unless otherwise stated in a credit line to the data. 
toll on most countries in South America, killing thousands in Brazil (121 100), Peru (28 800), Colombia (19 700), Chile (15 700), Argentina (8700), Ecuador (6600), and Bolivia (5000), thus far [3]. In addition to alreadystrained healthcare systems, other factors have affected the dynamics of the pandemic in the region, including migration, sociopolitical crises, struggling economies, other infectious disease outbreaks, poor leadership, and challenges tied to the implementation of social distancing, hygiene, and lockdown strategies, due to inadequate water and sanitation infrastructure and precarious living conditions [6, 8-15].

The Ministry of Health reported the first COVID-19 case in Chile on March 3, 2020 [16]. The government activated a quick response effort, announcing restrictions on large gatherings on March 13, and subsequently, closure of all daycares, schools, and universities (March 16), border controls, telework recommendations (March 18), closure of non-essential businesses (March 19), national night curfews (March 22), and a strategy of intermittent localized lockdowns in selected municipalities since March 26 [17]. Estimates for the early stage of the epidemic showed sustained transmission with an estimated reproduction number $R_{0}=1.8$ [95\% confidence interval $(C I)$ : 1.6-1.9] [18]. Research suggests that containment measures at the start of the epidemic significantly slowed down the spread of the virus in Chile [18]. Early models estimated that a surge in the number of ill patients could overwhelm treatment capacity by June unless aggressive control measures were implemented [19]. Control measures prevented the epidemic's growth in some regions, particularly during the first months of the epidemic [20-22].

Chile saw a rapid increase in reported COVID-19 cases during May, reaching a peak 7-day average incidence of about 6000 cases per day (31 per 100000 population) by mid-June [16]. Health system capacity reached saturation levels by the end of June, with 95\% intensive care unit occupancy in Greater Santiago and 89\% at the national level [23, 24]. As of August 31, the Ministry of Health's surveillance system EPIVIGILA has recorded a total of 444921 COVID-19 cases and 15756 deaths [16, 25]. Most of these reported COVID-19 cases and deaths have been confirmed by reverse transcription-polymerase chain reaction (RT-PCR) assay. However, these reported cases and deaths also include some clinically diagnosed COVID-19, particularly during the peak of the epidemic when the healthcare system reached saturation [23], and laboratories could not satisfy the demand for diagnostic tests. In June, 7-day average positivity rates of the RT-PCR tests reached 33\% nationally. Evidence shows that the circulation of other respiratory viruses, such as influenza, has been negligible in Chile and elsewhere in the southern hemisphere [26]. With 130 total RT-PCR tests per 1000 population by August 31, Chile has tested at a higher rate than any other Latin American country $[27,28]$.

During the first two months of the epidemic, the crude case fatality rate (CFR), the number of cumulative deaths over the number of cumulative cases, in Chile (1.2\%) remained well below the global average (6.5\%) [4, 16]. Because initial COVID-19 cases in Chile occurred among relatively low-risk groups (20-60 years of age), several infectious disease experts warned about authorities' excessive confidence over early success [29]. The CFR is a commonly used estimate of the severity of an epidemic [30]. It provides a reliable benchmark for public health officials to decide the intensity and duration of interventions to mitigate or suppress an epidemic [31]. Nevertheless, obtaining CFR estimates during an epidemic is challenging, as CFR is typically affected by right censoring and ascertainment bias [32-36]. Right-censoring occurs because of a time delay between the onset of symptoms and death, thus underestimating CFR. Underascertainment of cases occurs because mild or asymptomatic COVID-19 cases often go undetected by disease surveillance systems, which are not designed to detect all infections [33, 37, 38]. SARS-CoV-2 infection can result in a broad spectrum of clinical outcomes, including asymptomatic infection, mild symptoms, hospitalization, or death [39-41].

Here we provide real-time estimates of adjusted agespecific CFR during the COVID-19 epidemic in Chile, March through August 2020, to gauge the severity of the SARS-CoV-2 epidemic. These CFR estimates could inform critical decisions by public health officials in Chile and Latin America.

\section{Methods}

\section{Data sources}

We obtained daily cumulative numbers of reported COVID-19 cases and deaths stratified by age group and gender from March 3, 2020, through August 31, 2020, from the Ministry of Health's surveillance system EPIVIGILA [16, 25]. The datasets used are available from the Ministry of Science's COVID-19 repository [25]. COVID19 death definition follows the World Health Organization's updated guidelines for COVID-19 based on the International Statistical Classification of Diseases and Related Health Problems (ICD) standards [42]. Different groups had different starting times in the time series, which correspond to the day when the first death was reported. 


\section{Statistical analysis}

For the estimation of CFR in real-time, we employed the delay from hospitalization to death, $h_{s}$. We assumed $h_{s}=H(s)-H(s-1)$ for $s>0$ where $H(s)$ is a cumulative density function of the delay from hospitalization to death and follows a gamma distribution with mean 10.1 days and standard deviation (SD) 5.4 days [43]. Let $\pi_{a, t i}$ be the time-delay adjusted case fatality ratio on reported day $\mathrm{t}_{i}$ in area a, the likelihood function of the estimate $\pi_{a, t i}$ is the right parenthetical term. We assume that $D_{a, t i}$ is the result of the binomial sampling process with probability $\pi_{a, t i}$.

We estimated model parameters using a Monte Carlo Markov Chain (MCMC) method in a Bayesian framework. We evaluated the convergence of MCMC chains using the potential scale reduction statistic [46, 47]. Estimates and 95\% credibility intervals (CrI) for these estimates are based on each parameter's posterior prob-

$$
\left(\pi_{a, t_{i}} ; c_{a, t}, D_{a, t}\right)=\prod_{t_{i}}\left(\begin{array}{c}
\sum_{t=1}^{t_{i}} c_{a, t} \\
D_{a, t_{i}}
\end{array}\right)\left(\pi_{a, t_{i}} \frac{\sum_{t=2}^{t_{i}} \sum_{s=1}^{t-1} c_{a, t-s} h_{s}}{\sum_{t=1}^{t_{i}} c_{a, t}}\right)^{D_{a, t_{i}}}\left(1-\pi_{a, t_{i}} \frac{\sum_{t=2}^{t_{i}} \sum_{s=1}^{t-1} c_{a, t-s} h_{s}}{\sum_{t=1}^{t_{i}} c_{a, t}}\right)^{\sum_{t=1}^{t i} c_{a, t}-D_{a, t_{i}}}
$$

where $c_{a, t}$ represents the number of new cases with reported day $t$ in area $a$, and $D_{a, t i}$ is the cumulative number of deaths until reported day $\mathrm{t}_{i}$ in an area $a[44,45]$. Among the cumulative cases with reported day $t$ in area $a, D_{a, t i}$ have died, and the remainder have survived the infection. The contribution of those who have died with biased death risk is shown in the middle parenthetical term. The contribution of survivors is presented in ability distribution and based on the samples drawn from the posterior distributions.

All statistical analyses were conducted in $\mathrm{R}$ version 3.6.1 (R Foundation for Statistical Computing, Vienna, Austria) using the 'rstan' package. This research was considered exempt from ethical review because it is limited to secondary data analysis based on publicly available data $[16,25]$, which contains no information that can

Table 1 Distribution of the COVID-19 cases in Chile by sex and age groups, as of August 31, 2020

\begin{tabular}{|c|c|c|c|c|c|c|c|c|}
\hline \multirow[t]{3}{*}{ Age group } & \multicolumn{4}{|l|}{ Men } & \multicolumn{4}{|l|}{ Women } \\
\hline & \multirow{2}{*}{$\begin{array}{l}\text { Cases } \\
(\%)\end{array}$} & \multirow{2}{*}{$\begin{array}{l}\text { Deaths } \\
\text { (\%) }\end{array}$} & \multirow[t]{2}{*}{ CCFR (\%) } & \multirow[t]{2}{*}{$\begin{array}{l}\text { Mortality per } 100 \\
000 \text { population }\end{array}$} & \multirow{2}{*}{$\begin{array}{l}\text { Cases } \\
(\%)\end{array}$} & \multirow{2}{*}{$\begin{array}{l}\text { Deaths } \\
\text { (\%) }\end{array}$} & \multirow[t]{2}{*}{ CCFR (\%) } & \multirow[t]{2}{*}{$\begin{array}{l}\text { Mortality per } 100 \\
000 \text { population }\end{array}$} \\
\hline & & & & & & & & \\
\hline \multirow[t]{2}{*}{ All } & 227642 & 9035 & 3.97 & 105.0 & 217279 & 6721 & 3.09 & 74.9 \\
\hline & $(100)$ & $(100)$ & & & $(100)$ & (100) & & \\
\hline \multirow[t]{2}{*}{$0-9$} & 8357 & 17 & 0.20 & 1.4 & 7864 & 16 & 0.20 & 1.4 \\
\hline & (3.7) & $(0.2)$ & & & (3.6) & $(0.2)$ & & \\
\hline \multirow[t]{2}{*}{$10-19$} & 11505 & 13 & 0.11 & 1.1 & 12692 & 7 & 0.06 & 0.6 \\
\hline & (5.1) & $(0.1)$ & & & (5.8) & $(0.1)$ & & \\
\hline \multirow[t]{2}{*}{$20-29$} & 45736 & 62 & 0.14 & 4.3 & 45649 & 35 & 0.08 & 2.5 \\
\hline & (20.1) & $(0.7)$ & & & $(21.0)$ & $(0.5)$ & & \\
\hline \multirow[t]{2}{*}{$30-39$} & 51596 & 163 & 0.32 & 13.1 & 46201 & 86 & 0.19 & 6.8 \\
\hline & $(22.7)$ & $(1.8)$ & & & $(21.3)$ & (1.3) & & \\
\hline \multirow[t]{2}{*}{$40-49$} & 38870 & 359 & 0.92 & 31.2 & 35426 & 197 & 0.56 & 16.3 \\
\hline & $(17.1)$ & $(4.0)$ & & & $(16.3)$ & (2.9) & & \\
\hline \multirow[t]{2}{*}{$50-59$} & 35543 & 1061 & 2.99 & 99.2 & 33012 & 520 & 1.58 & 44.7 \\
\hline & (15.6) & $(11.7)$ & & & $(15.2)$ & (7.7) & & \\
\hline \multirow[t]{2}{*}{$60-69$} & 21215 & 2057 & 9.70 & 292.7 & 18788 & 1148 & 6.11 & 144.0 \\
\hline & (9.3) & (22.8) & & & (8.6) & (17.1) & & \\
\hline \multirow[t]{2}{*}{$70-79$} & 9908 & 2669 & 26.94 & 687.1 & 10015 & 1726 & 17.23 & 351.5 \\
\hline & $(4.4)$ & $(29.5)$ & & & (4.6) & $(25.7)$ & & \\
\hline \multirow[t]{2}{*}{$80-$} & 4912 & 2634 & 53.62 & 1528.9 & 7632 & 2986 & 39.12 & 1000.4 \\
\hline & $(2.2)$ & $(29.2)$ & & & (3.5) & $(44.4)$ & & \\
\hline
\end{tabular}


directly or indirectly identify an individual. All data used in this analysis are publicly available [25].

\section{Results \\ Epidemiological characterization of COVID-19 in Chile}

The Ministry of Health has reported 444921 COVID19 cases and 15756 deaths as of August 31 [16, 25]. For men, most reported cases were persons aged $30-39$ years $(22.7 \%)$, followed by $20-29$ year-olds (20.1\%) and 40-49 year-olds (17.1\%) (Table 1). Most reported deaths were seniors, especially 70-79 yearolds $(29.5 \%)$, followed by those aged 80 years and older (29.2\%), and 60-69 year-olds (22.8\%) (Table 1, Fig. 1a, b). We found a similar pattern for women, except that most deaths were reported among women aged 80 years and older $(44.4 \%)$.

The proportion of male cases is higher than 50\% across age groups, except for 10-19 year-olds, $70-79$ year-olds, and those aged 80 years and above $\left(\chi^{2}\right.$ test, $P$-value $<0.0001$, Fig. $1 \mathrm{c})$. The proportion of male deaths is higher than $50 \%$ except for those aged 80 years and above $\left(\chi^{2}\right.$ test, $P<0.0001$, Fig. $1 \mathrm{~d}$ ). Figure 1e presents the cumulative morbidity ratio by gender and age group. The ratio of illness among males is significantly higher than among females across most age groups (proportion test, $P<0.000$ ), except for $10-19$ year-olds (proportion test, $P<0.00$ ) and $20-29$ year-olds (proportion test, $P=0.01$ ). We found no statistically significant differences for $0-9$ year-olds (proportion test, $P=0.19$ ).

We found that mortality per 100000 population directly caused by COVID-19 among males is higher than among females for all age groups 20 years and above (proportion test, $P<0.05$, Fig. 1f). We found no statistically significant differences for individuals aged $0-19$ years.

\section{Evolution of cases and deaths by age group}

The reported cumulative COVID-19 cases and deaths by age group and gender (A through J) over time are shown in Fig. 2. The figure suggests cumulative cases of COVID19 are growing faster than cumulative deaths. The growth curve for cumulative cases across all age groups increases exponentially after around day 30 (April 30, 2020) until around day 80 (June 19, 2020). Exponential growth in cumulative deaths for all age groups occurs approximately after day 45 (May 15, 2020).

\section{Crude and time-delay adjusted risk of death}

The observed and model-based posterior estimates of the crude CFR of COVID-19 by age group (A-J) and time-delay adjusted CFR by age group (K-T) are shown in Fig. 3. Black dots show crude case-fatality ratios, and light and dark indicate $95 \%$ and $50 \%$ credible intervals for posterior estimates, respectively.

Overall, our model-based crude CFR fitted the observed data well. Crude CFR for all age groups (J) increased at an early stage of the epidemic, and once peaked around April 25 and was followed by an increase in CFR. There is an increasing CFR trend across most age groups, starting around May 10, 2020. Our model-based posterior estimates for the time-delay adjusted CFR are substantially higher than the crude observed CFR at an early stage. Both values are converging as the epidemic progresses.

The time-delay adjusted CFR results by gender and age group, as of August 31,2020, are shown in Table 2 and Fig. 4. Time-delay adjusted CFR for men and women are $4.16 \%$ (95\% CrI: $4.09-4.24 \%$ ) and $3.26 \%$ (95\% CrI: 3.19-3.34\%), respectively, while overall national estimate is $3.72 \%$ (95\% CrI: $3.67-3.78 \%$ ). Among men, senior citizens appear to be severely affected; the adjusted CFR is $10.16 \%$ (95\% CrI: 9.76-10.60\%) for men aged 60-69 years, $28.35 \%$ (95\% CrI: $27.49-29.35 \%$ ) for those aged $70-79$ years, and $56.82 \%$ (95\% CrI: $55.25-58.34 \%$ ) for those 80 years old and above. We observe a similar pattern for women. The adjusted CFR is $6.44 \%$ (95\% CrI: 6.10-6.81\%) for women aged 60-69 years, $18.18 \%(95 \%$ CrI: $17.40-18.93 \%)$ for those aged 70-79 years, and $41.10 \%$ (95\% CrI: $40.02-42.26 \%$ ) for women aged 80 years old or more.

\section{Discussion}

Few studies have estimated the time-delay adjusted CFR by age group for COVID-19 in Latin America [48], a region with relatively little attention during the ongoing coronavirus pandemic. Consistent with other recent COVID-19 research [31, 33, 49], our results show that the COVID-19 epidemic in Chile has disproportionately affected seniors, especially those aged $\geq 70$ years. These results suggest that an aging population could exacerbate the fatality impact of COVID-19 [50], similar to influenza and respiratory syncytial virus [51], and consistent with data available from Italy [50]. The comparatively low CFR observed in Chile during the early stages of the epidemic [29] probably reflected the initial cases' age structure and socioeconomic status. During the first weeks of the pandemic, COVID-19 cases occurred among relatively young age groups, with most transmission occurring among individuals between 20 and 60 years of age, and in highincome communities with better access to healthcare and lower prevalence of risk factors for severe COVID-19 [13, $14,16,21,52,53]$.

Our latest adjusted CFR estimates for those aged 80 and over reach values as high as 56.82\% (95\%CrI: $55.25-$ 58.34 ) for men and $41.10 \%$ (95\%CrI: $40.02-42.26 \%)$ for 

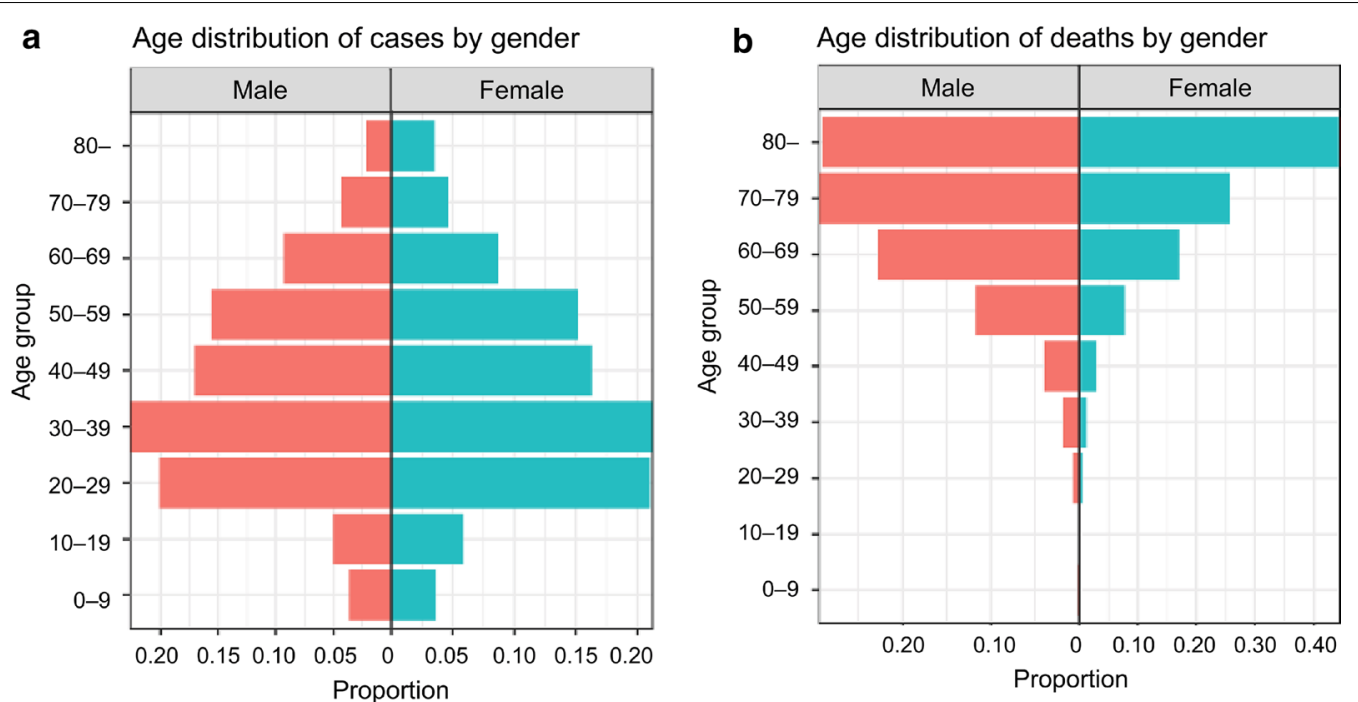

c Gender proportion of COVID-19 cases by age group

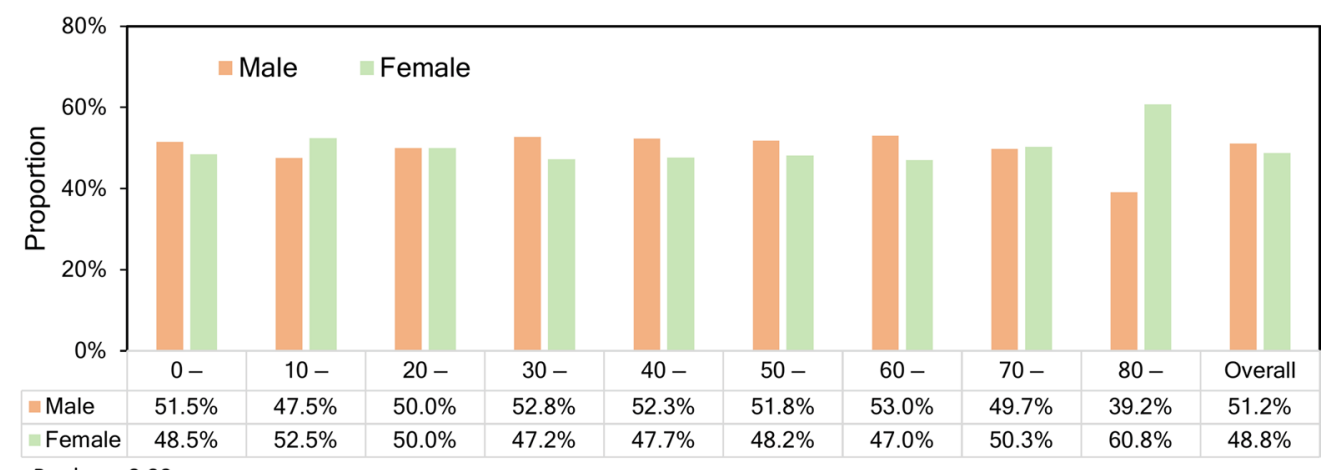

$P$ value $<0.00$

Age group

d Gender proportion of COVID-19 deaths by age group

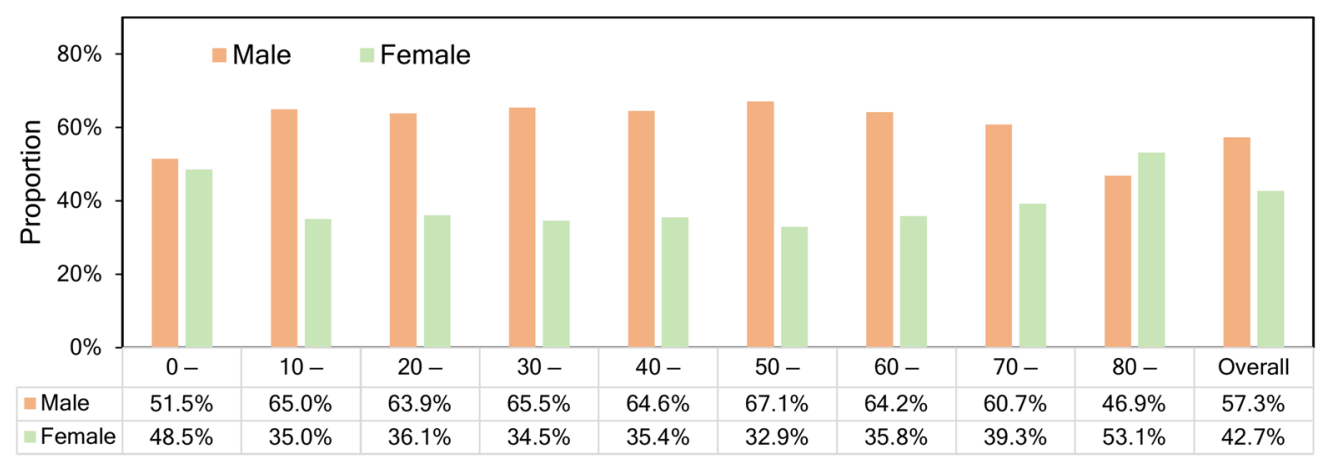

$P$ value $<0.00 \quad$ Age group

Fig. 1 Epidemiological characterization of COVID-19 in Chile, as of August 31, 2020. a Age distribution of reported cases by gender. b Age distribution of reported deaths by gender. $\mathbf{c}$ Gender proportion of COVID-19 cases by age group. $\mathbf{d}$ Gender proportion of COVID-19 deaths by age group. e Cumulative morbidity risk by gender and age group. $\mathbf{f}$ Mortality directly caused by COVID-19 by gender and age group

women. Adjusted CFR for men aged 80 years of age and older is 2.0-fold higher than our estimates for men aged 70-79 years and 5.6-fold higher than men aged 60-69.
Adjusted CFR for women 80 years of age and older is 2.3-fold higher than our estimates for women aged 70-79 years and 6.4-fold higher than women aged 60-69. 


\section{e Cumulative morbidity ratio by gender and age group}

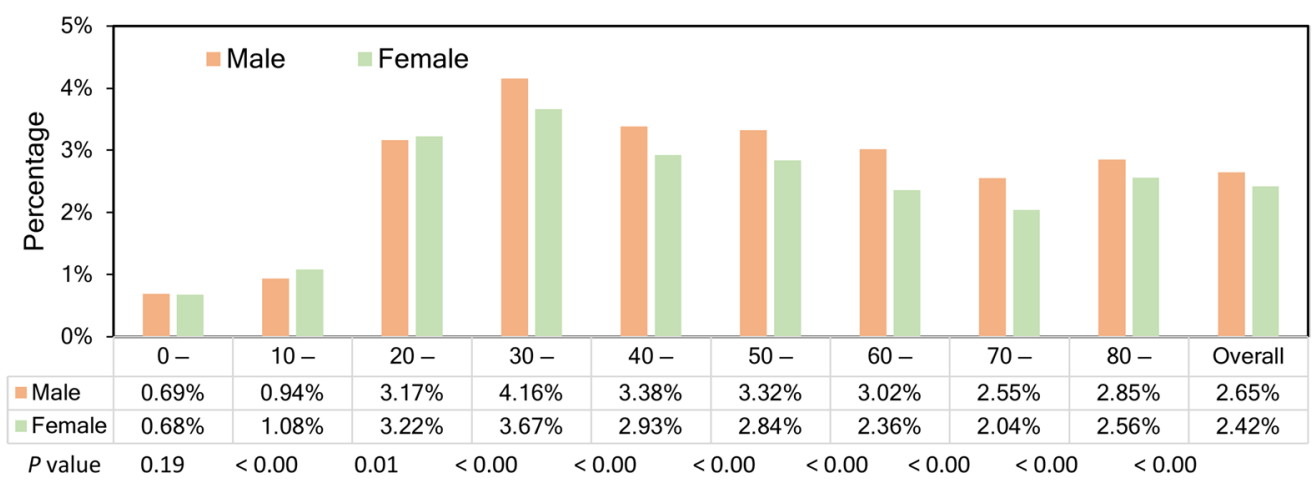

Age group

f Mortality directly caused by COVID-19 by gender and age group

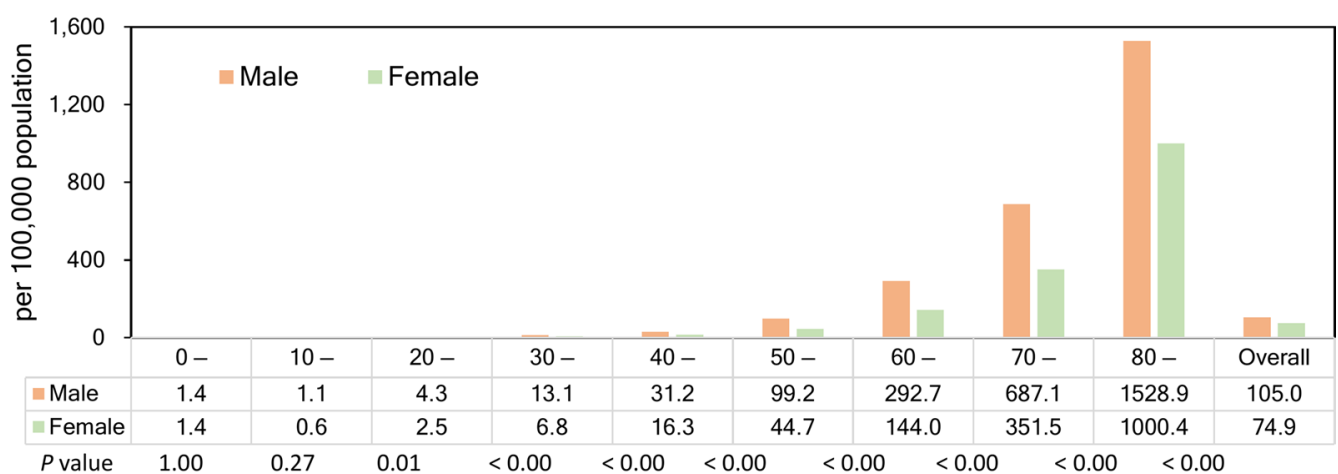

Age group

Fig. 1 continued

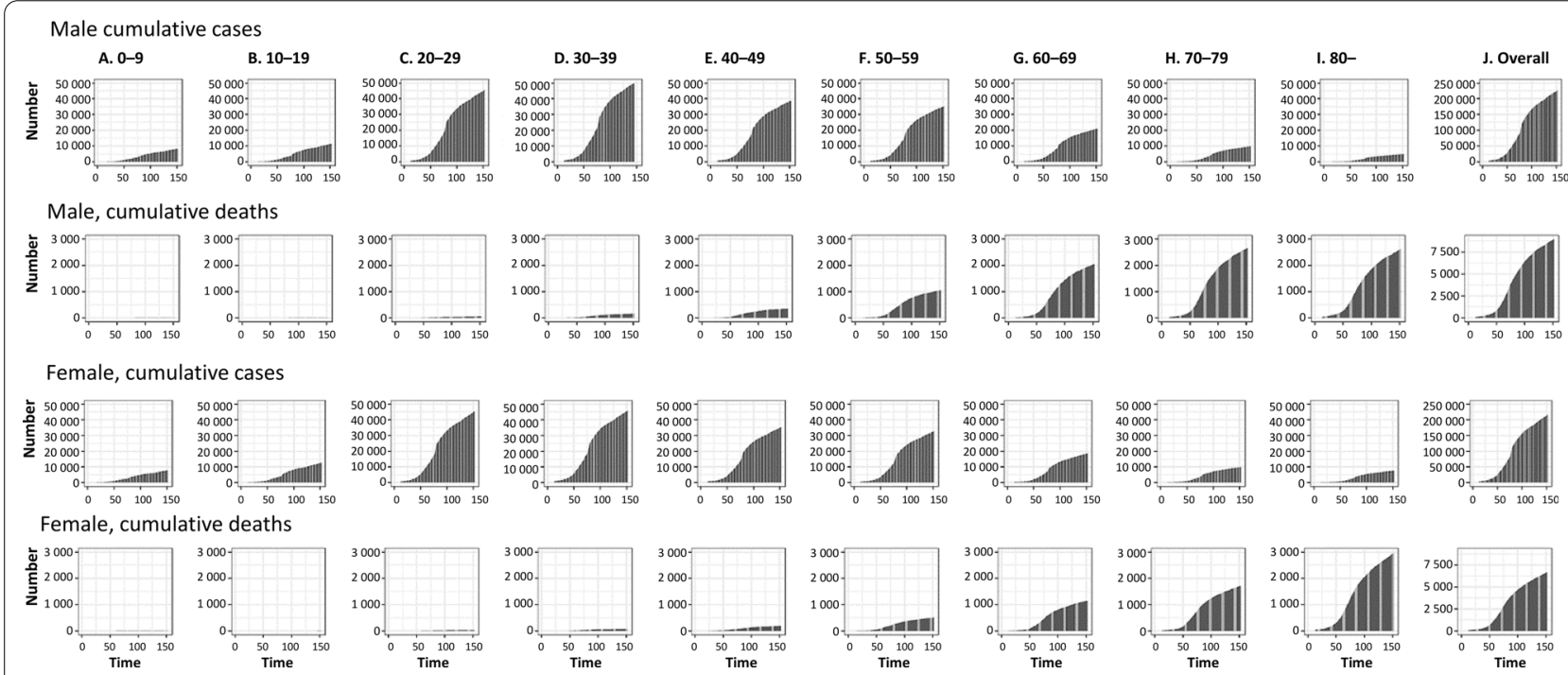

Fig. 2 Temporal distribution of COVID-19 cases and deaths by age group, April through August 31, 2020, Chile. Cumulative cases and deaths of COVID-19 for men (first and second rows) and women (third and fourth rows) for the following age groups a 0-9, b 10-19, c 20-29, d 30-39, e 40-49, f 50-59, $\mathbf{g} 60-69, \mathbf{h} 70-79, \mathbf{i} 80$ years or more, (N) all fatal cases over time. Day 1 corresponds to April 1 in 2020. Because the dates of illness onset were not available, we used dates of reporting by the Ministry of Health 
The large majority (68.4\%) of COVID-19 cases occurred in Greater Santiago during the study period. As seen for the overall population starting in April until about day 75 (June 14), the upward trend in the crude CFR suggests that viral transmission was spreading to more vulnerable populations. Interestingly, throughout March, most transmissions occurred among relatively young, betteroff populations. In Greater Santiago, localized lockdowns were put in place starting March 28 through mid-April in seven municipalities, six of which are among the richest in Chile [54]. Viral transmission moved towards lowerincome municipalities during April [16, 21]. Among these economically disadvantaged populations, social distancing measures are harder to comply with due to a higher proportion of the population participating in the informal economy, greater population density and overcrowding, more deficient sanitary infrastructure, and lower quality healthcare $[14,21,55]$. Estimates of human mobility during the city-wide lockdown based on cellphone data across municipalities show that the lockdown was less effective in lower-income municipalities $[14,56]$. The higher the rate of multidimensional poverty (based on education, health, labor, housing, and social capital), the less effective was the lockdown in reducing mobility, with up to a three-fold difference in mobility reductions between rich and poor municipalities in Santiago. The disproportionate impact that the COVID-19 pandemic has had on lower-income or more vulnerable populations has also been documented elsewhere $[5,57,58]$.

a Male crude case fatality ratio by age group, observed and estimated
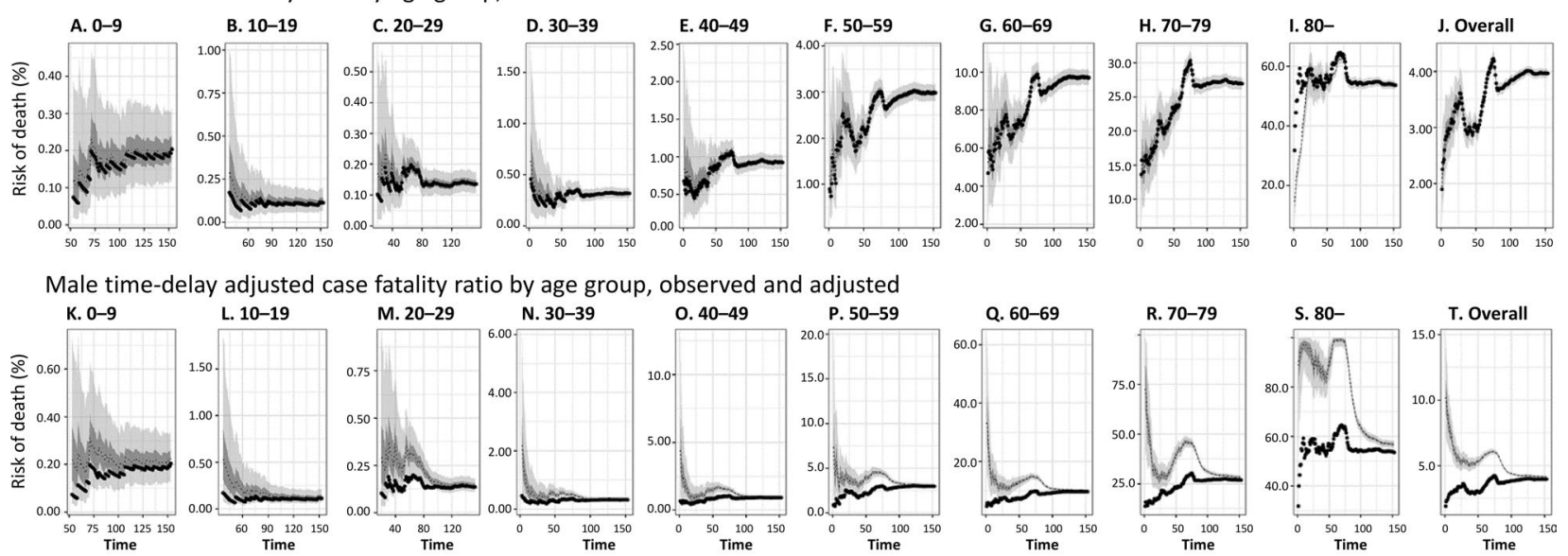

b
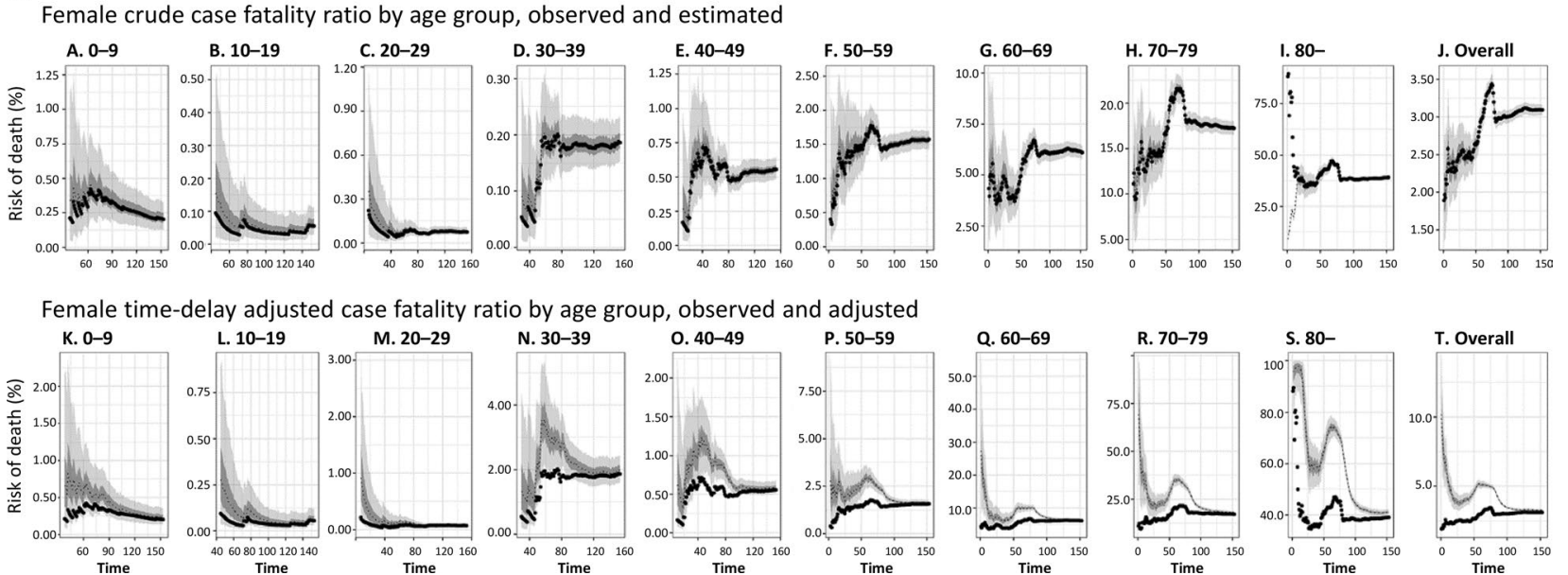

Fig. 3 Temporal variation of risk of death caused by COVID-19, April through August 19, 2020, Chile. Upper two rows; Male risk of death, Lower two rows; Female risk of death. Observed and posterior estimated of crude case fatality ratio of persons aged a 0-9, b 10-19, c 20-29, d 30-39, e 40-49, f 50-59, $\mathbf{g} 60-69, \mathbf{h} 70-79, \mathbf{i} 80$ and more, and $\mathbf{j}$ all age groups. Time-delay adjusted case fatality ratio of persons aged $\mathbf{k} 0-9, \mathbf{0} 40-49, \mathbf{p} 50-59$, q $60-69, \mathbf{r} 70-79, \mathbf{s} 80$ and more, and $\mathbf{t}$ all age groups. Day 1 corresponds to April 1, 2020. Black dots show crude case fatality ratio, and light and dark indicate $95 \%$ and $50 \%$ credible intervals for posterior estimates, respectively 
An upward trend in the crude CFR could also have resulted from an increasing number of unreported cases due to a saturated testing capacity [55]. Chile's testing capabilities were greatly expanded during the epidemic, partly as a coordinated effort from the Ministry of Science to include testing from public and private laboratories, including universities that converted research labs to PCR testing labs. Processing capacity grew from a few hundred tests per day to up to 35000 per day (cumulative of about 130 tests per 1000 population) so far [25]. Despite this massive increase in testing capabilities, the 7-day average test positivity (positive tests/total tests) reached 33\% nationally and $48 \%$ in Greater Santiago during the mid-June peak of the epidemic. This dramatic increase in positive test rates suggests there may be a substantial proportion of under-diagnosed COVID-19 cases in Chile, at least during the peak of transmission in Greater Santiago [59].

The health system capacity also reached saturation levels during the pandemic's peak by the end of June, with 95\% intensive care unit occupancy in Greater Santiago and $89 \%$ at the national level [23, 24]. A major disease outbreak, such as COVID-19, can strain the healthcare system and hospital resources [19]. This excess demand may potentially degrade treatment quality or lead to sub-optimal treatment decisions, such as diversion from hospitalization or early discharge, and cause delays in laboratory work and reporting, as has been observed in other public health emergencies [60-62]. However, our data do not allow us to test this hypothesis.

The downward trend in the adjusted CFR at the early stage of the study period may have been influenced by reporting delays. The observed differences in our crude and adjusted CFR estimates are directly due to the timedelay, which we assume fixed during the epidemic.

The small proportion of men (39.2\%) among COVID19 cases in people aged 80 and over is probably attributable to the relatively small male population size for that age group; men represent only $37 \%$ of the population $>80$ in Chile [63]. Life expectancy at birth in Chile is 77.2 years for men and 82.1 years for women. Life expectancy at age 60 is 21.8 years for men and 24.9 years for women. China and the United States have reported higher mortality among men [64, 65]; our data provide the opportunity to examine the CFR by gender and age.

Table 2 Summary results of time-delay adjusted case fatality risk of COVID-19 by age group and gender in Chile, 2020 (August 31, 2020)

\begin{tabular}{|c|c|c|c|c|}
\hline Age group & Gender & Latest estimate $\left(95 \% \mathrm{Crl}^{\mathrm{a}}\right)$ & $\begin{array}{l}\text { Range of median } \\
\text { estimates }\end{array}$ & $\begin{array}{l}\text { Crude case fatality rate }(95 \% \\
\left.\mathrm{Cl}^{\mathrm{b}}\right)\end{array}$ \\
\hline Overall & & $3.72 \%(3.67-3.78 \%)$ & $3.72-9.94 \%$ & $3.54 \%$ (3.49-3.60\%) \\
\hline Male & & $4.16 \%(4.09-4.24 \%)$ & $4.16-10.20 \%$ & $3.97 \%$ (3.90-4.05\%) \\
\hline Female & & $3.26 \%$ (3.19-3.34\%) & $3.26-10.19 \%$ & $3.09 \%(3.02-3.17 \%)$ \\
\hline \multirow[t]{2}{*}{$0-9$} & Male & $0.23 \%(0.13-0.34 \%)$ & $0.17-0.31 \%$ & $0.21 \%(0.12-0.32 \%)$ \\
\hline & Female & $0.23 \%(0.14-0.35 \%)$ & $0.23-0.83 \%$ & $0.21 \%(0.13-0.33 \%)$ \\
\hline \multirow[t]{2}{*}{ 10-19 } & Male & $0.13 \%(0.07-0.22 \%)$ & $0.11-0.53 \%$ & $0.12 \%(0.07-0.20 \%)$ \\
\hline & Female & $0.06 \%(0.03-0.12 \%)$ & $0.04-0.28 \%$ & $0.06 \%(0.03-0.11 \%)$ \\
\hline \multirow[t]{2}{*}{$20-29$} & Male & $0.14 \%(0.11-0.18 \%)$ & $0.14-0.38 \%$ & $0.14 \%(0.11-0.17 \%)$ \\
\hline & Female & $0.08 \%(0.06-0.11 \%)$ & $0.08-0.92 \%$ & $0.08 \%(0.06-0.11 \%)$ \\
\hline \multirow[t]{2}{*}{$30-39$} & Male & $0.33 \%(0.28-0.39 \%)$ & $0.33-2.18 \%$ & $0.31 \%(0.27-0.37 \%)$ \\
\hline & Female & $0.20 \%(0.16-0.24 \%)$ & $0.10-0.36 \%$ & $0.19 \%(0.15-0.23 \%)$ \\
\hline \multirow[t]{2}{*}{$40-49$} & Male & $0.96 \%(0.87-1.07 \%)$ & $0.86-4.42 \%$ & $0.92 \%(0.84-1.02 \%)$ \\
\hline & Female & $0.59 \%(0.51-0.67 \%)$ & $0.32-1.24 \%$ & $0.56 \%(0.49-0.64 \%)$ \\
\hline \multirow[t]{2}{*}{$50-59$} & Male & $3.12 \%(2.94-3.31 \%)$ & $2.76-7.36 \%$ & $2.99 \%(2.81-3.17 \%)$ \\
\hline & Female & $1.66 \%(1.52-1.80 \%)$ & $1.63-3.02 \%$ & $1.58 \%(1.45-1.72 \%)$ \\
\hline \multirow[t]{2}{*}{$60-69$} & Male & $10.16 \%$ (9.76-10.60\%) & $10.16-33.29 \%$ & $9.69 \%(9.31-10.10 \%)$ \\
\hline & Female & $6.44 \%$ (6.10-6.81\%) & $5.98-27.32 \%$ & $6.11 \%(5.78-6.45 \%)$ \\
\hline \multirow[t]{2}{*}{$70-79$} & Male & $28.35 \%$ (27.49-29.35\%) & $27.27-72.74 \%$ & 26.97\% (26.15-27.92\%) \\
\hline & Female & $18.18 \%$ (17.40-18.93\%) & $18.16-69.30 \%$ & $17.25 \%(16.51-17.96 \%)$ \\
\hline \multirow[t]{2}{*}{$80-$} & Male & $56.82 \%$ (55.25-58.34\%) & $56.82-99.26 \%$ & $53.62 \%$ (52.14-55.05\%) \\
\hline & Female & $41.10 \%$ (40.02-42.26\%) & $40.80-97.86 \%$ & $39.13 \%$ (38.10-40.23\%) \\
\hline
\end{tabular}

\footnotetext{
${ }^{a} \mathrm{Crl}$ credibility intervals

b $\mathrm{Cl}$ confidence interval

c Cumulative cases over cumulative deaths
} 


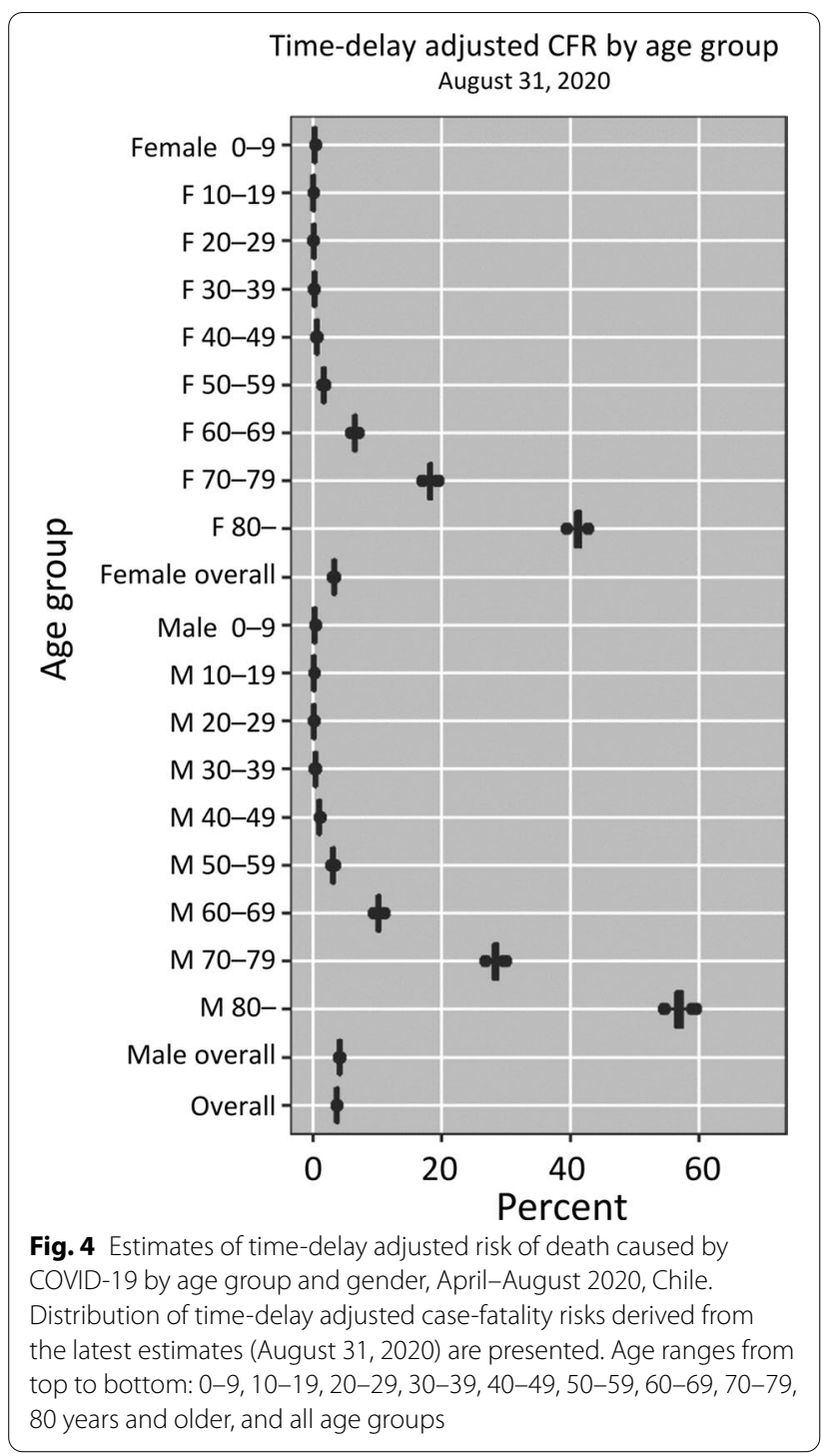

Our study has limitations. First, our CFR estimates are probably affected by under ascertainment, as has been estimated elsewhere [33, 37, 38]. Under ascertainment may have pushed our estimates upwards if the surveillance system captured the most severe cases. This bias may be particularly problematic during the peak of the epidemic from mid-May through the end of June. Infectious diseases with a substantial share of asymptomatic or mild infections, such as COVID-19, may be more accurately characterized by infection-fatality risk (deaths / infected people). However, those data are not yet available in Chile. Second, we used laboratory-confirmed and probable COVID-19 cases in our analysis, which may result in an overestimation of COVID-19 cases and thus may have pushed our CFR estimates downwards. The demand for diagnostic tests exceeded laboratory capacity in Chile during the peak of the epidemic, as suggested by high rates of positive tests [16]. Test positivity reached a 7 -day average of $33 \%$ nationally and $48 \%$ at the peak of the epidemic in Greater Santiago, suggesting that a substantial proportion of cases were left without testing. In our favor, the circulation of other respiratory viruses has been of no importance during the COVID-19 pandemic in Chile and elsewhere [26] in the southern hemisphere.

\section{Conclusion}

Using real-time epidemiological data from a high COVID-19 testing setting in Latin America, we found that the COVID-19 epidemic in Chile has disproportionately affected seniors, especially those aged $\geq 70$ years, suggesting an aging population could exacerbate the death toll brought by the emergence of SARS-CoV-2 . COVID-19 is already imposing a high death toll in Latin America. These real-time estimates may help inform public health officials' decisions in the region and underscore the need to implement more effective measures to ameliorate mortality, especially among those facing the highest risk of death.

\section{Acknowledgements \\ Not applicable.}

\section{Authors' contributions}

GC and KM conceived the initial study idea. KM implemented statistical analysis. GC, KM, EU contributed to the study implementation, interpretation of results, and writing of the manuscript. All authors read and approved the final manuscript.

\section{Funding}

This work was supported by the Japan Society for the Promotion of Science (JSPS) KAKENHI [Grant 20H03940]; the Leading Initiative for Excellent Young Researchers from the Ministry of Education, Culture, Sport, Science \& Technology of Japan; Japan Science and Technology Agency (JST) J-RAPID [Grant JPMJJR2002] to KM; National Science Foundation NSF [Grant 1414374] as part of the joint NSF-National Institutes of Health NIH-United States Department of Agriculture USDA Ecology and Evolution of Infectious Diseases program; UK Biotechnology and Biological Sciences Research Council [Grant BB/M008894/1] to GC; and the ANID Millennium Science Initiative [Grant NCN17_081] to EU. The study sponsors had no role in the study design, collection, analysis, and interpretation of data; in the writing of the manuscript; and in the decision to submit the manuscript for publication.

\section{Availability of data and materials}

The datasets used and analyzed during the current study are available from Base de Datos COVID-19 repository, http://www.minciencia.gob.cl/covid19.

\section{Ethics approval and consent to participate}

This research was considered exempt from ethical review because it is limited to secondary data analysis based on publicly available data $[16,25]$, which contains no information that can directly or indirectly identify an individual.

\section{Consent for publication}

Not applicable.

\section{Competing interests}

The authors (EU, GC, KM) declare that they have no competing interests. 


\begin{abstract}
Author details
${ }^{1}$ Escuela de Gobierno, Pontificia Universidad Católica de Chile, Vicuña Mackenna 4860, Macul, CP 7820436 Santiago, Región Metropolitana, Chile. ${ }^{2}$ Millennium Initiative for Collaborative Research in Bacterial Resistance (MICROB-R), Santiago, Chile. ${ }^{3}$ Department of Population Health Sciences, School of Public Health, Georgia State University, Atlanta, GA, USA. ${ }^{4}$ Graduate School of Advanced Integrated Studies in Human Survivability, Kyoto University Yoshida-Nakaadachi-Cho, Sakyo-ku, Kyoto, Japan. ${ }^{5}$ Hakubi Center for Advanced Research, Kyoto University, Yoshidahonmachi, Sakyo-ku, Kyoto, Japan.
\end{abstract}

Received: 9 June 2020 Accepted: 16 December 2020

Published online: 03 February 2021

\section{References}

1. Walker PGT, Whittaker C, Watson OJ, Baguelin M, Winskill P, Hamlet A, et al. The impact of COVID-19 and strategies for mitigation and suppression in low- and middle-income countries. Science. 2020;369(6502):413-22.

2. Flaxman S, Mishra S, Gandy A, Unwin HJT, Mellan TA, Coupland H, et al. Estimating the effects of non-pharmaceutical interventions on COVID-19 in Europe. Nature. 2020;584:257-61.

3. Dong E, Du H, Gardner L. An interactive web-based dashboard to track COVID-19 in real time. Lancet Infect Dis. 2020;20(5):P533-4.

4. World Health Organization. Coronavirus Disease (COVID-19) Outbreak Geneva:WHO. 2020. https://www.who.int/emergencies/diseases/novel -coronavirus-2019. Accessed 18 Nov 2020.

5. de Souza WM, Buss LF, Candido DdS, Carrera J-P, Li S, Zarebski AE, et al. Epidemiological and clinical characteristics of the COVID-19 epidemic in Brazil. Nat Hum Behav. 2020;4:856-65.

6. Burki T. COVID-19 in Latin America. Lancet Infect Dis. 2020;20(5):547-8.

7. Garcia PJ, Alarcón A, Bayer A, Buss P, Guerra G, Ribeiro H, et al. COVID-19 response in Latin America. Am J Trop Med Hyg. 2020;103(5):1765-72.

8. Lancet T. The unfolding migrant crisis in Latin America. Lancet. 2019;394(10213):1966

9. Fetzer TR, Witte M, Hensel $L$, Jachimowicz J, Haushofer J, Ivchenko A, et al. Global behaviors and perceptions at the onset of the COVID-19 pandemic. NBER. 2020;No. 27082.

10. Navarro JC, Arrivillaga-Henríquez J, Salazar-Loor J, Rodriguez-Morales AJ. COVID-19 and dengue, co-epidemics in Ecuador and other countries in Latin America: pushing strained health care systems over the edge. Travel Med Infect Dis. 2020;37:101656.

11. Kirby T. South America prepares for the impact of COVID-19. Lancet Respir Med. 2020a;8(6):551-2.

12. World Bank. The Economy in the Time of CoVID-19 Washington DC: World Bank. 2020. https://bit.ly/35B2r3y. Accessed 18 Apr 2020.

13. Adhikari SP, Meng S, Wu Y-J, Mao Y-P, Ye R-X, Wang Q-Z, et al. Epidemiology, causes, clinical manifestation and diagnosis, prevention and control of coronavirus disease (COVID-19) during the early outbreak period: a scoping review. Infect Dis Poverty. 2020;9(1):29.

14. Gil M, Undurraga EA. CoVID-19 has exposed how'the other half' (still) lives. Bull Lat Am Res. 2020;39(S1):28-34.

15. Barberia LG, Gómez EJ. Political and institutional perils of Brazil's COVID19 crisis. Lancet. 2020;396(10248):367-8.

16. Ministerio de Salud. Cifras Oficiales COVID-19 Santiago: Ministry of Health, Plan de Acción Coronavirus COVID-19. 2020. https://www.gob.cl/coron avirus/cifrasoficiales/. Accessed 23 Sept 2020.

17. Ministerio de Salud. Plan de acción por coronavirus Santiago: Ministerio de Salud, Gobierno de Chile. 2020. https://www.gob.cl/coronavirus/pland eaccion/. Accessed 18 Nov 2020

18. Tariq A, Undurraga EA, Laborde CC, Vogt-Geisse K, Luo R, Rothenberg R, et al. Transmission dynamics and control of COVID-19 in Chile: MarchOctober, 2020. PLOS Negl Trop Dis. (in press).

19. Rainisch G, Undurraga EA, Chowell G. A dynamic modeling tool for estimating healthcare demand from the COVID19 epidemic and evaluating population-wide interventions. Int J Infect Dis. 2020;96:P376-83.

20. LiY, Undurraga EA, Zubizarreta JR. Effectiveness of localized lockdowns in the SARS-CoV-2 pandemic. medRxiv. 2020. https://doi. org/10.1101/2020.08.25.20182071.
21. Bennett M. All things equal? Heterogeneity in policy effectiveness against COVID-19 spread in Chile. World Dev. 2021;137:105208.

22. Cuadrado C, Monsalves MJ, Gajardo J, Bertoglia MP, Najera M, Alfaro T, et al. Impact of small-area lockdowns for the control of the COVID-19 pandemic. medRxiv. 2020. https://doi.org/10.1101/2020.05.05.20092106.

23. Canals M, Cuadrado C, Canals A, Yohannessen K, Lefio LA, Bertoglia MP, et al. Epidemic trends, public health response and health system capacity: the Chilean experience in four months of the COVID-19 pandemic. Rev Panam Salud Publica. 2020;44:e99.

24. Sociedad Chilena de Medicina Intensiva SOCHIMI. Encuesta nacional sobre ocupación de unidades críticas durante contingencia CoVID-19 Santiago, Chile: Universidad Finis Terrae. 2020. https://medicina-inten siva.cl/site/covid/img/noticias/informe_22MY2020.pdf. Accessed 23 Sept 2020.

25. Ministerio de Ciencia Tecnología Conocimiento e Innovación. Base de datos CoVID-19 Santiago de Chile: Ministerio de Ciencia, Tecnología, Conocimiento, e Innovación. 2020. http://www.minciencia.gob.cl/covid 19. Accessed 23 Sept 2020.

26. Olsen SJ, Azziz-Baumgartner E, Budd AP, Brammer L, Sullivan S, Pineda RF, et al. Decreased influenza activity during the COVID-19 pandemicUnited States, Australia, Chile, and South Africa, 2020. Morb Mortal Wkly Rep. 2020;69(37):1305-9.

27. Thomson E, Sanders P. Prognosis. Chile charts new path with rolling lockdowns, immunity cards. 2020. https://www.bloomberg.com/news/artic les/2020-04-22/with-immunity-cards-and-rolling-lockdowns-chile-forge s-own-path. Accessed 18 Nov 2020.

28. Roser M, Ritchie H, Ortiz-Ospina E, Hasell J. Coronavirus pandemic (COVID-19). 2020. https://bit.ly/2ROHdts. Accessed 18 Nov 2020.

29. McGowan C. Chile doctors fear complacency over Covid-19 after initial successes. The Guardian. 2020. 10 April. https://bit.ly/2IMqNQS. Accessed 18 Nov 2020

30. Reed C, Biggerstaff M, Finelli L, Koonin LM, Beauvais D, Uzicanin A, et al. Novel framework for assessing epidemiologic effects of influenza epidemics and pandemics. Emerg Infect Dis. 2013;19(1):85.

31. Mizumoto K, Chowell G. Estimating risk for death from 2019 novel coronavirus disease, China, January-February 2020. Emerg Infect Dis. 2020;26(6):10-3201.

32. Li R, Pei S, Chen B, Song Y, Zhang T, Yang W, et al. Substantial undocumented infection facilitates the rapid dissemination of novel coronavirus (COVID-19). Science. 2020;368(6490):489-93.

33. Hauser A, Counotte MJ, Margossian CC, Konstantinoudis G, Low N, Althaus $\mathrm{CL}$, et al. Estimation of SARS-CoV-2 mortality during the early stages of an epidemic: a modeling study in Hubei, China, and six regions in Europe. PLoS Med. 2020;17(7):e1003189.

34. Ghani AC, Donnelly CA, Cox DR, Griffin JT, Fraser C, Lam TH, et al. Methods for estimating the case fatality ratio for a novel, emerging infectious disease. Am J Epidemiol. 2005;162(5):479-86.

35. Jewell NP, Lei X, Ghani AC, Donnelly CA, Leung GM, Ho LM, et al. Nonparametric estimation of the case fatality ratio with competing risks data: an application to Severe Acute Respiratory Syndrome (SARS). Stat Med. 2007;26(9):1982-98.

36. Lipsitch M, Donnelly CA, Fraser C, Blake IM, Cori A, Dorigatti I, et al. Potential biases in estimating absolute and relative case-fatality risks during outbreaks. PLoS Negl Trop Dis. 2015;9(7):e0003846.

37. Jung S-m, Akhmetzhanov AR, Hayashi K, Linton NM, Yang Y, Yuan B, et al. Real-time estimation of the risk of death from novel coronavirus (COVID19) infection: inference using exported cases. J Clin Med. 2020;9(2):523.

38. Pan A, Liu L, Wang C, Guo H, Hao X, Wang Q, et al. Association of public health interventions with the epidemiology of the COVID-19 outbreak in Wuhan, China. JAMA. 2020;323(19):1915-23.

39. Guan W-j, Ni Z-y, Hu Y, Liang W-h, Ou C-q, He J-x, et al. Clinical characteristics of coronavirus disease in China. N Engl J Med. 2020;382:1708-20.

40. Cao J, Hu X, Cheng W, Yu L, Tu W-J, Liu Q. Clinical features and short-term outcomes of 18 patients with corona virus disease 2019 in intensive care unit. Intensive Care Med. 2020;46:851-3.

41. Wu JT, Leung K, Bushman M, Kishore N, Niehus R, de Salazar PM, et al. Estimating clinical severity of COVID-19 from the transmission dynamics in Wuhan, China. Nat Med. 2020;26:506-10.

42. World Health Organization. International guidelines for certification and classification (coding) of COVID-19 as cause of death Geneva: WHO. 2020. 
https://www.who.int/classifications/icd/covid19/en/. Accessed 10 Sept 2020.

43. Mizumoto K, Kagaya K, Zarebski A, Chowell G. Estimating the asymptomatic proportion of coronavirus disease 2019 (COVID-19) cases on board the Diamond Princess cruise ship, Yokohama, Japan, 2020. Eurosurveillance. 2020;25(10):2000180.

44. Nishiura H, Klinkenberg D, Roberts M, Heesterbeek JA. Early epidemiological assessment of the virulence of emerging infectious diseases: a case study of an influenza pandemic. PLoS ONE. 2009;4(8):e6852.

45. Tsuzuki S, Lee H, Miura F, Chan YH, Jung S-m, Akhmetzhanov AR, et al. Dynamics of the pneumonic plague epidemic in Madagascar, August to October 2017. Eurosurveillance. 2017;22(46):17-00710.

46. Gamerman D, Lopes HF. Markov chain Monte Carlo: stochastic simulation for Bayesian inference. Boca Raton: CRC Press; 2006.

47. Gelman A, Rubin DB. Inference from iterative simulation using multiple sequences. Stat Sci. 1992;7(4):457-72.

48. Munayco C, Chowell G, Tariq A, Undurraga EA, Mizumoto K. Risk of death by age and gender from CoVID-19 in Peru, March-May, 2020. Aging. 2020;12(14):13869-81.

49. Feng Z, Li Q, Zhang Y, Wu Z, Dong $X$, Ma H, et al. The epidemiological characteristics of an outbreak of 2019 novel coronavirus diseases (COVID19)-China, 2020. China CDC Wkly. 2020;2(8):113-22.

50. Dowd JB, Andriano L, Brazel DM, Rotondi V, Block P, Ding X, et al. Demographic science aids in understanding the spread and fatality rates of COVID-19. Proc Natl Acad Sci USA. 2020;117(18):9696-8.

51. Mizumoto K, Chowell G, Simonsen L, Nishiura H. The burden of influenza and respiratory syncytial viruses in Japan, 2006-2014: a region-and agespecific excess mortality study. Int J Infect Dis. 2019;79:96-7.

52. Zhou F, Yu T, Du R, Fan G, Liu Y, Liu Z, et al. Clinical course and risk factors for mortality of adult inpatients with COVID-19 in Wuhan, China: a retrospective cohort study. Lancet. 2020;395(10229):1054-62.

53. Wang $B, L i R$, Lu Z, Huang Y. Does comorbidity increase the risk of patients with COVID-19: evidence from meta-analysis. Aging. 2020;12(7):6049-57.

54. Sistema Nacional de Información Municipal. Datos Municipales Santiago. 2020. http://datos.sinim.gov.cl/datos_municipales.php. Accessed 10 Sept 2020
55. Cociña M, Frei R, Larrañaga O. Desiguales: Orígenes, cambios y desafíos de la brecha social en Chile: Programa de las Naciones Unidas para el Desarrollo (PNUD); 2017.

56. Arroyo C, Engel E, Pardow D, Simonetti P. Informe sobre la evolución de la epidemia de Covid-19 en Chile, 30 de mayo 2020 Santiago de Chile. 2020. https://bit.ly/3e5wy6L. Accessed 18 Nov 2020.

57. Kirby T. Evidence mounts on the disproportionate effect of COVID-19 on ethnic minorities. Lancet Respir Med. 2020b;8(6):547-8.

58. Tai DBG, Shah A, Doubeni CA, Sia IG, Wieland ML. The disproportionate impact of COVID-19 on racial and ethnic minorities in the United States. Clin Infect Dis. 2020. https://doi.org/10.1093/cid/ciaa815.

59. Asahi K, Undurraga EA, Valdes R, Wagner R. The effect of COVID-19 on the economy: evidence from an early adopter of localized lockdowns. J Glob Health. 2021. (in press).

60. Parpia AS, Ndeffo-Mbah ML, Wenzel NS, Galvani AP. Effects of response to 2014-2015 Ebola outbreak on deaths from malaria, HIV/AIDS, and tuberculosis, West Africa. Emerg Infect Dis. 2016;22(3):433.

61. Cotter C, Sturrock HJ, Hsiang MS, Liu J, Phillips AA, Hwang J, et al. The changing epidemiology of malaria elimination: new strategies for new challenges. Lancet. 2013;382(9895):900-11.

62. Evans DK, Goldstein M, Popova A. Health-care worker mortality and the legacy of the Ebola epidemic. Lancet Glob Health. 2015;3(8):e439-40.

63. Instituto Nacional de Estadísticas (INE). Estimaciones y proyecciones de la población de Chile 1992-2050 Santiago: INE. 2017. https://www.censo 2017.cl/. Accessed 18 Nov 2020

64. Richardson S, Hirsch JS, Narasimhan M, Crawford JM, McGinn T, Davidson KW, et al. Presenting characteristics, comorbidities, and outcomes among 5700 patients hospitalized with COVID-19 in the New York City area. JAMA. 2020;323(20):2052-9.

65. The Novel Coronavirus Pneumonia Emergency Response Epidemiology Team. The epidemiological characteristics of an outbreak of 2019 novel coronavirus diseases (COVID-19)—China, 2020. China CDC Wkly. 2020;2(8):113-22
Ready to submit your research? Choose BMC and benefit from:

- fast, convenient online submission

- thorough peer review by experienced researchers in your field

- rapid publication on acceptance

- support for research data, including large and complex data types

- gold Open Access which fosters wider collaboration and increased citations

- maximum visibility for your research: over $100 \mathrm{M}$ website views per year

At BMC, research is always in progress.

Learn more biomedcentral.com/submissions 